\title{
COMPILING AN EUROPEAN IMMIGRATION HISTORY
}

\section{THE CASE OF LAND OF PROMISE}

\author{
Andrea Meuzelaar \\ Media and Culture Studies, Utrecht University \\ Muntstraat 2A \\ 3512 EV Utrecht \\ The Netherlands \\ A.Meuzelaar@uu.nl
}

\begin{abstract}
Today, television's reliance on archival footage seems to be intensifying due to the improved accessibility of European broadcast archives and the increased amount of available digitized broadcast material. This article presents an analysis of a recently broadcast Dutch television series, Land van Aankomst ('Land of Promise,' 2014), which has benefitted significantly from the improved accessibility of broadcast archives and the increased availability of digitized broadcast material. This three-part Dutch television series narrates the history of post-war immigration in Europe and is constructed from archival footage from various European broadcast archives. This article analyses the compilation strategy of Land of Promise and assesses what kind of European immigration history the series articulates through the selection and juxtaposition of archival footage.
\end{abstract}

Keywords: archival compilation; immigration history in Europe; televisual historiography; European broadcast archives; Land of Promise.

\section{Introduction}

While the televisual practice of compiling (hi)stories from archival footage is not a new phenomenon, television's reliance on archival footage seems to be intensifying due to the increased accessibility of (European) broadcast archives. Currently, various European broadcast archives are making considerable efforts to digitize their collections, to improve accessibility and to facilitate reuse of their material. Large digitization projects such as Images for the Future and several (inter)national research projects to improve access to audio-visual heritage have resulted in an unprecedented availability and accessibility of (digitized) archival material. ${ }^{1}$ An urgent question that arises is whether all these efforts by broadcast archives to facilitate the reuse of their holdings result in new forms and practices of televisual historiography. How do media professionals actually use the large amount of available footage? What kind of compilation strategies do they resort to? What kind of histories do they articulate through (digitized) archival stock footage? 
In this article I present an analysis of a recently broadcast Dutch television series Land van Aankomst ('Land of Promise,' 2014) $)^{2}$ and argue that the abundance of archival material does not necessarily lead to innovative forms of televisual historiography. This three-part television series narrates the history of post-war immigration in Europe and is constructed completely out of retrieved footage from various European broadcast archives. Certainly, Land of Promise is symptomatic of the archival impulse that is the result of the improved accessibility of European broadcast archives and the increased availability of digitized European broadcast material. ${ }^{3}$ In terms of its archival aspirations, Land of Promise is quite an unique project: not only because it has brought together such a vast amount of footage from various European broadcast archives, but also because its archival approach is more radical than most conventional archivereliant historical television programs since it exclusively relies on archival footage for its visuals.

In the following sections I analyse the compilation strategy of Land of Promise and assess what kind of European immigration history the series has articulated through the selection and juxtaposition of archival footage. I argue that the narrative of immigration history that Land of Promise articulates is exceedingly historicist in character; that the series has mainly selected footage because it is evocative or dramatic; that the generic reuse of this footage results in the loss of its historical specificity; and that the didactic tone of Land of Promise's narrative not only amplifies the strong impression of authenticity and of history unfolding in front of the camera that archival images inherently have, but also conceals the underlying selectivity of the archival images that are edited into Land of Promise's seamless and smooth story.

\section{A Three-Part Television Series: 'Avoidance', 'Conflict' and 'Acceptance'}

The television series Land of Promise was written and directed by Dutch filmmaker René Roelofs and author Paul Scheffer, ${ }^{4}$ and its narrative of European post-war immigration history is inspired by Scheffer's well-known book Het Land van Aankomst (2007). ${ }^{5}$ The television series was first broadcast on Dutch television in January 2014 and was part of the output of a larger production that has also released a feature documentary (Land of Promise, 2013) that was shown in various art-house cinemas. ${ }^{6}$ Both the feature documentary and the television series present their account of European post-war immigration history through a thematic sequencing of excerpts from Dutch, British, French, German, Belgian and Swedish news and current affairs magazines and talk shows that were retrieved from various European broadcast archives, such as the Netherlands Institute of Sound and Vision, the Belgian VRT, the French INA, the German WDR and NDR, BBC Motion Gallery and British Pathé. Only music, few captions, and-in the case of the series-a voice-over have been added to the archival footage. In this article I focus on the television series only, since I am interested in televisual forms of archival compilation.

The series consists of three episodes (each around 40 minutes) and explicitly aims to tell a hopeful story about immigration; it makes the argument that large-scale immigration first leads to avoidance by both parties, that it unavoidably results in conflicts, and that these conflicts eventually lead to integration and reconciliation. By showing that this is the case everywhere in Europe-in Sweden, France, the UK, Belgium, Germany and the Netherlands-the series reaches out to an international audience and urges its viewers to put obsessions with immigration and Islam in a broader European perspective. The series was nominated for the PRIX EUROPA (2014), and has since been broadcast in various European countries. ${ }^{7}$

2 Throughout this article I adhere to the English translation that is used by the producers (Interakt/NTR/IKON) to promote and sell the series in the transnational context.

3 For example, the project has benefitted significantly from the digitization project Images for the Future; a lot of the Dutch footage that the series displays has been digitized within the context of this project.

4 Paul Scheffer is the author of the influential and contested article "The Multicultural Drama" (NRC Handelsblad, 29 January 2000). In this article Scheffer declared the Dutch multicultural society bankrupt and stated that integration had failed. The publishing of this article was the overture for the hardening of the Dutch debate on integration in the 2000's. He is currently Professor of European Studies at Tilburg University.

5 Paul Scheffer, Het Land van Aankomst, De Bezige Bij, 2007.

6 The feature documentary premiered at the International Documentary Festival Amsterdam (28 November 2013). The three-part television series was broadcast on 8, 15 and 22 January 2014 by NTR/IKON (and repeated on 5, 12 and 19 July 2015).

7 The series was nominated in the category TV IRIS (Best European Intercultural TV Programme). 
The first episode ('Avoidance,') tells the story of the arrival of postcolonial and labour immigrants in the various European countries, the miserable housing situation of the immigrants, the (racist) reactions of the local populations, and the period of mutual avoidance that followed. The second episode ('Conflict,') revolves around the conflicts that arose as a consequence of migration. It tells the story of the arrival of the children of the immigrants, the generational conflicts that followed, various riots in places such as Bradford (UK), Husby (Sweden), Molenbeek (Belgium) and the banlieus in France, and the discomfort among the autochthonous population with the arrival of the 'new' religion of Islam. And finally, the third episode ('Acceptance,') revolves around the struggle over the place of Islam in the various European societies, which (according to the series) has resulted in the end of multiculturalism. The episode shows naturalisation ceremonies in various European countries and tells the stories of successful people of immigrant descent. It ends with the statement that all this proves that the struggle over immigration and Islam has finally resulted in the acceptance of a new reality. Before assessing what kind of immigration history Land of Promise has articulated, it is useful to have a closer look at the formal qualities and the appropriation strategy of the series.

\section{Land of Promise's Strategy of Archival Compilation}

Although Land of Promise's archival approach is more far-reaching than most conventional archive-reliant historical television programmes-since it completely relies on archival footage for its visuals and shows unusually lengthy sequences of archival footage without explanatory voice-over-its overall organizing logic is quite similar. Like most of television's historical documentaries, Land of Promise shares many of the formal and stylistic qualities of what Bill Nichols terms 'the expository mode' of documentary. ${ }^{8}$ These are documentaries that address the viewer directly with titles or a voice-over, that "advance an argument about the historical world", "rely heavily on the informing logic carried out by the spoken word", and invite the viewer to understand the images as "evidence or illustration of what is said."

The voice-over that steers Land of Promise's narration is that of a disembodied, omniscient, male narrator-an archetypal 'voice of God'-that imposes its interpretative framework in a didactic manner. Although the narration is by Paul Scheffer himself, which could convey the story as a personal and subjective enterprise, this is not made explicit. Scheffer mostly remains detached from the images commented upon, and the overall authoritative tonality of the voiceover signposts the story above all as a factual account of immigration history. Already in the opening address of Episode 1 (00:00-02:54), the voice-over sets a positivist tone when it introduces the topic of this episode with the phrase: "do we actually remember how it all began?" In the rest of the series, Scheffer's voice-over persistently gives the impression that we are watching history unfold.

Furthermore, the voice-over operates in a conventional manner, namely to anchor the meaning of the images, set out an argument, impose unity on the divergent archival images, enforce a cause-effect structure and offer a closure of the story. The lengthy sequences of archive footage are constantly connected and made sense of by pre-emptive and concluding pieces of voice-over that guide the audience's response to the archival footage. For example, in the opening address of Episode 3 (00:03.10), the voice-over presents the argument that will be made, makes sense of the montage of archival images that will follow, and logically binds these images together. Finally, even during the protracted moments of silence, the preceding, connecting and closing pieces of voice-over assure a limited potential for ambivalence and alternative interpretations.

In spite of this, the series' appropriation strategy is more ambiguous than most expository archive-reliant programs. In her work on the reemplotment of actuality footage in documentary, Rebecca Swender points to the limitations of Nichols' taxonomy for accounting for this documentary practice: "While Nichols's taxonomy is an eminently useful tool for identifying many of the specifics of how documentaries address spectators, it does not differentiate among documentary types on the question of the reemplotment of existing footage into secondary texts." ${ }^{\text {10 }}$ In her New Documentary, Stella Bruzzi argues that archival material is primarily used in one of two ways: "illustratively, as part of a

8 Bill Nichols, Introduction to Documentary, Indiana University Press, 2010, p. 167.

9 Nichols, p. 167-168.

10 Rebecca Swender, "Claiming the Found: Archive Footage and Documentary Practice," The Velvet Light Trap, 64, Fall 2009, p. 9. 
historical explanation to complement other elements such as interviews and voice-over, or critically as a more politicised historical argument or debate." ${ }^{11}$ According to Bruzzi, the first is the strategy used by most conventional television documentaries and is straightforward in the sense that "it is not asking the spectator to question the archival documents but simply to absorb them as a component of a larger narrative." ${ }^{12}$ Swender designates this appropriation strategy "naturalization":

Archive footage can be incorporated into a secondary text in a manner that draws more or less attention to the "past lives" of the archive footage [...]. Archive footage is naturalized when the capacity for the instability of meaning is deemphasized. ${ }^{13}$

For the most part, Land of Promise's appropriation strategy is conventional. The footage is predominantly reemplotted in such a way that it does not draw attention to its origin or its "past lives"14 and conveys the story that is invoked by Scheffer's voice-over. The filmmakers combine material that has high historical specificity with more generic archival material, and its reemplotment serves to support the voice-over's truth claim about the course of history. The interplay between archival footage and voice-over offers a cumulative understanding of the immigration history that is being told. The thematic sequencing of the material, the added music, and the statements articulated by the people depicted and by the original voice-overs of the footage all support the preferred reading of the material verbalized by Scheffer's voiceover. The footage is treated as generically figurative, since the viewer is denied information about the actual events that the images depict and the editing is merely used to prove the argument made by the voice-over, a style of editing that Nichols has coined 'evidentiary editing. ${ }^{15}$

At certain moments, however, the series' usage of archival material affiliates it with the documentary tradition of what Bruzzi describes as "compilation film"16: documentaries that are constructed almost exclusively out of retrieved archival material, adopt a critical use of archival material and are "democratic in the sense that they do not openly intervene."17 In her elaboration of the long-standing and complex history of this critical approach to archival footage (pioneered by the Soviet filmmakers Esther Shub and Dziga Vertov in the 1920s), Bruzzi describes compilation films as "rooted to the idea that meaning is constructed through editing [...] they use archival material provocatively and dialectically and compel audiences to think, to question and to seek change". ${ }^{18}$ Compilation films, in Bruzzi's conception, play on the complexity of the relationship between the historical referent and the interpretation and use the polemical potential of archival footage to offer an (ironic) critique of history and/or media representations. Through contrapuntal editing, these films can create a dialectical collusion between the inherent perspective of the original footage and its re-appropriation.

Although this is certainly not the dominant compilation strategy in Land of Promise, at certain moments its usage of archival material transcends its main function as a mere illustration of history and becomes a critical commentary on history. In particular in the first episode, the selection of the material, the editing, and the added music result in a narrative about the initial years of immigration that is simultaneously a critique of the way guest workers and postcolonial immigrants were treated. For example, in the first lengthy sequence of archival footage in the episode 'Avoidance' (03:00-19:18), the editing and juxtaposition of footage of recruitments and medical examinations as well as the added music underscore the critical potential of the original material. In the other two episodes, however, the archival footage is more straightforwardly used as mere illustration, and its polemic potential is only sporadically activated by the editing.

Finally, Land of Promise presents itself above all as a historical-didactic series about post-war immigration in Europe rather than as a (personal) essay that presents a critique of this history. The didactic tone and the commentary of the voice-over invite the viewer to regard the archival images as glimpses of the past rather than as a critique of (media

11 Stella Bruzzi, New Documentary: A Critical Introduction, Routledge, 2000, p. 21.

12 Bruzzi, p. 21.

13 Swender, p. 9

14 Swender, p.9.

15 Nichols, p. 25.

16 Bruzzi, p. 21.

17 Bruzzi, p. 39

18 Bruzzi, p. 23. 
representations of) the past. If archival footage gives access to the mediated past and thus always has a double historical meaning -it documents both historical events and the history of broadcasting ${ }^{19}$ — Land of Promise's direct address narration mainly activates the first meaning and intensifies the strong impression of authenticity and of history unfolding in front of the camera that archival images already inherently have. Given that the related feature documentary does not employ a direct address narration and thus renders much more freedom to the audience to interpret the footage, it is likely that the series' conventional and compelling mode of narration is prompted by public television's mandate to inform. Apparently, television demands a pedagogical instead of a more democratic mode of historiography. Now what kind of migration history has the series articulated?

\section{Compiling a Historicist Narrative}

First, what is striking is that the narrative of the European immigration history that Land of Promise articulates is exceedingly historicist in character. Historicism is a feature that applies to many programs that rely on archival footage and often results in simplistic and schematic representations of the past. As Allan Sekula phrases it:

for historicism, the archive confirms the existence of a linear progression from past to present [...]. At their worst, pictorial histories offer an extraordinary reductive view of historical causality: the First World War "begins" with a glimpse of an assassination in Sarajevo. ${ }^{20}$

Clearly, the narration of Land of Promise imposes a linear development on the history of migration that is explicitly informed by the present "confusion" over migration and Islam. Land of Promise's history lesson openly functions as a comforting tale: there is hope for the future, because history has proven that immigration unavoidably first leads to avoidance and conflict, but eventually to reconciliation. The archival footage is selected and sequenced to illustrate and support this narrative, to show that this linear development-from the arrival of the single male guest worker, to suburban riots and angry Muslim mobs, to final reconciliation-applies to the entirety of Europe, and to demonstrate that various geographically separate events, conflicts and developments have similar causes and are the symptoms of the inevitable course of history. Obviously, this is quite a determinist and simplistic account of history.

Both the selection and sequencing of archival footage are at the service of the historicist view of history that the series promotes. The archival material seems to be picked merely because it has the capacity to visually reinforce the argument about immigration history that the series advances. Both in the case of historical specific footage and in the case of more generic footage, the archival images are above all treated as emblematic; they are constantly reused in a generic manner to represent the various stages in the immigration history that the voice-over illuminates. In order to tell its historicist narrative, the series thus homogenizes and generalizes the meaning of the archival footage and disregards the specific historical context of the events that the footage depicts. The narration suggests, both explicitly through the voice-over and implicitly through editing, a linear progression from the first to the last stage and insinuates that the succession of archival footage is by and large faithful to historical chronology. At various moments, the series uses captions to designate the year of origin of the material and thereby openly communicates its violations of chronology. At other moments, the series is less explicit about its juxtapositions of images that originate from very different historical contexts and, in the case of footage with a high historical specificity, appeals to the prior knowledge of the audience to notice this.

This narrative strategy of imposing a linear development on European immigration history results in sustaining visual linkages between events that are temporally very separate and events that are unalike in terms of their historical meaning. For example, in the first part of Episode 3, 'Acceptance,' (03:17-19:25), the voice-over states that over the course of the nineties a fierce controversy over the settlement of Islam developed. A lengthy sequence of archival footage (without captions and voice-over) illustrates this statement (see Figure 1 for a selection of stills from the sequence) e.g., an excerpt from a Belgian report on female Muslims demonstrating for the right to wear hijab, an excerpt from a Swedish report about an honour killing (thereby implying that honour killings are inherent to Islam), 
British footage of a parade of Muslims celebrating Muhammad's day of birth, footage of demonstrations against the British Indian novelist Salman Rushdie and book burnings in Britain, footage of the Rushdie affair in the Netherlands, footage of the Danish Cartoon Crisis, an excerpt of an interview with Dutch politician Ayaan Hirsi Ali, and footage of the murder of Dutch filmmaker Theo van Gogh and the demonstration in Amsterdam that followed.
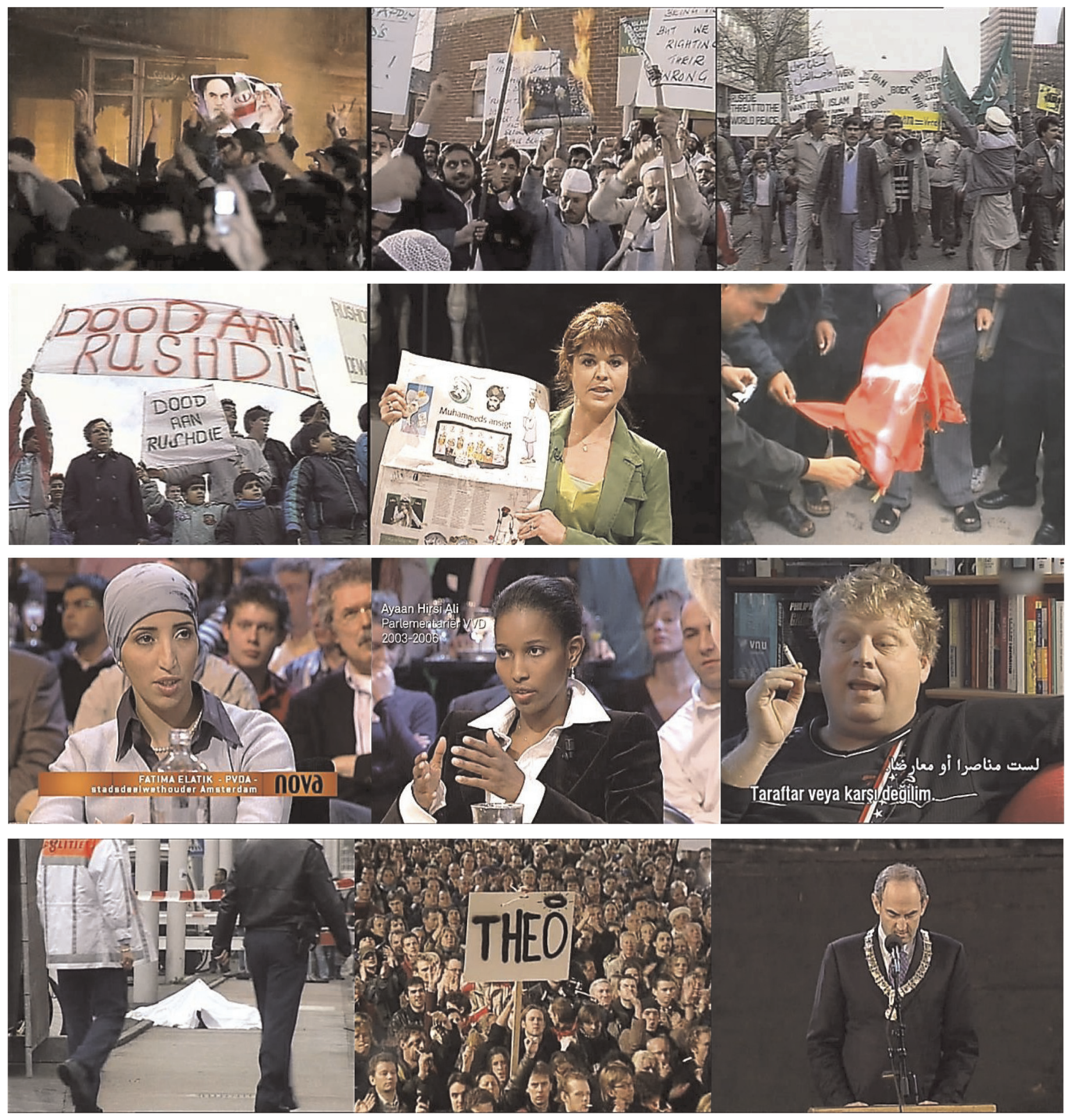

Figure 1. A selection of stills from the above described sequence in Land of Promise Episode 3, 'Acceptance.' 
Apart from the imagery of the Rushdie affair (1989), this sequence only shows footage that originates from the first decade of the new century. The footage of the Rushdie affair appears in the middle of the sequence (10:46-12:30), and there is no caption that designates the Rushdie footage as originating from 1989. In this manner, the series disregards the time-lapse between the Rushdie affair and the upheaval about Islam that occurred in the 2000s. The voice-over and editing generalize the meaning of the Rushdie footage as yet another example of angry Muslims who disrespect freedom of expression, render them within a continuum of the threat of Islam, and implicitly suggest a direct linear development from the Rushdie affair to the murder of van Gogh. Thereby the series draws historical analogies between events that are asymmetrical in terms of their historical meaning.

This is only one example of the general historicist strategy of archival compilation that the series employs, often disregarding the historical specificity of the footage. In the second episode, 'Conflict,' the voice-over states that after the period of mutual avoidance, conflicts emerged as a result of family reunification and the dissolution of the belief that the presence of labour immigrants was of a temporary nature. The first archival sequence (03.28-10:56) shows footage from the seventies, eighties and nineties of various European politicians who critically address the issue of immigration and then shows various scenes from a famous episode of the Dutch current affairs magazine Televizier about riots against Turkish guest workers in the Afrikaanderwijk in Rotterdam in 1972 (08:33-10.56).

Although there is a caption saying "Rotterdam, 1972", this footage is treated generically and as emblematic for the stage of conflict that resulted from the discovery that immigration was irreversible. Yet the riots in the Afrikaanderwijk occurred before the dissolution of the belief in the temporariness of the stay of immigrants and before family reunification; the stakes were housing issues (discontent of autochtonen about the growing amount of pensions for guest workers at the expense of housing for natives). Strictly speaking, the footage thus belongs in Episode 1, which revolves around the initial years of immigration and dedicates a sequence to housing issues. However, since the footage contradicts the main theme of avoidance of the first episode, it is shown in Episode 2 to visually illustrate the stage of conflict. When compared to the original footage, it becomes clear that the filmmakers have selected the very scenes that are most fitting to demonstrate conflict (and have excluded the scenes in which the underlying causes of the riots are being addressed), scenes that furthermore are generic enough that the alteration of their original sequencing goes unnoticed. In this case, the expressiveness of the footage overtakes its historical meaning, and the footage becomes a mere generalization at the service of Land of Promise's historicist narrative.

\section{Migration History as a Visual Spectacle}

Obviously, the Televizier footage of the riots in the Afrikaanderwijk was picked not only because of its capacity to illustrate conflict but also because it is especially evocative. Not surprisingly, the Dutch press reviews of Land of Promise have highlighted these very images, and described them as "racial riots" that are "shocking." 21 Much of the archival footage that the series displays seems to be selected because it is evocative, dramatic or remarkable. And while this footage is what makes the series so memorable, its generic reuse results in the loss of its historical specificity. The consequence-I would argue-is that the history of this footage stays mute and what remains is a visual spectacle that does not really tell us much about the past. For example, the sequence in Episode 2 of footage of statements made by various European politicians described above (03:38-12:39) also shows material of the Dutch prime minister Ruud Lubbers who talks to the camera in Arabic and encourages people to vote (12:14-12:22). ${ }^{22}$ This is quite remarkable footage, but since there is no contextualisation by the voice-over, it is unclear what the footage is actually depicting. The footage is no longer capable of evoking anything else but amazement and becomes a mere gesture.

Besides, while the first episode exhibits much fascinating and unfamiliar archival footage, in the course of the second and the third episode, Land of Promise increasingly becomes a succession of déjà-vu images that slide toward interchangeability. For example, a lengthy sequence in Episode 2 consists of a juxtaposition of images of riots and

21 See, for example, the reviews in NRCHandelsblad (16 January 2014) and Filmkrant (December 2013).

22 The footage derives from an episode of Televizier, broadcast 7 March 1986. It is an infomercial in which prime minister Ruud Lubbers requests the Moroccan community to come and vote in the municipal elections. In 1986, immigrants were given the right to vote in local elections, and Lubbers was trying to mobilize this new electorate. 


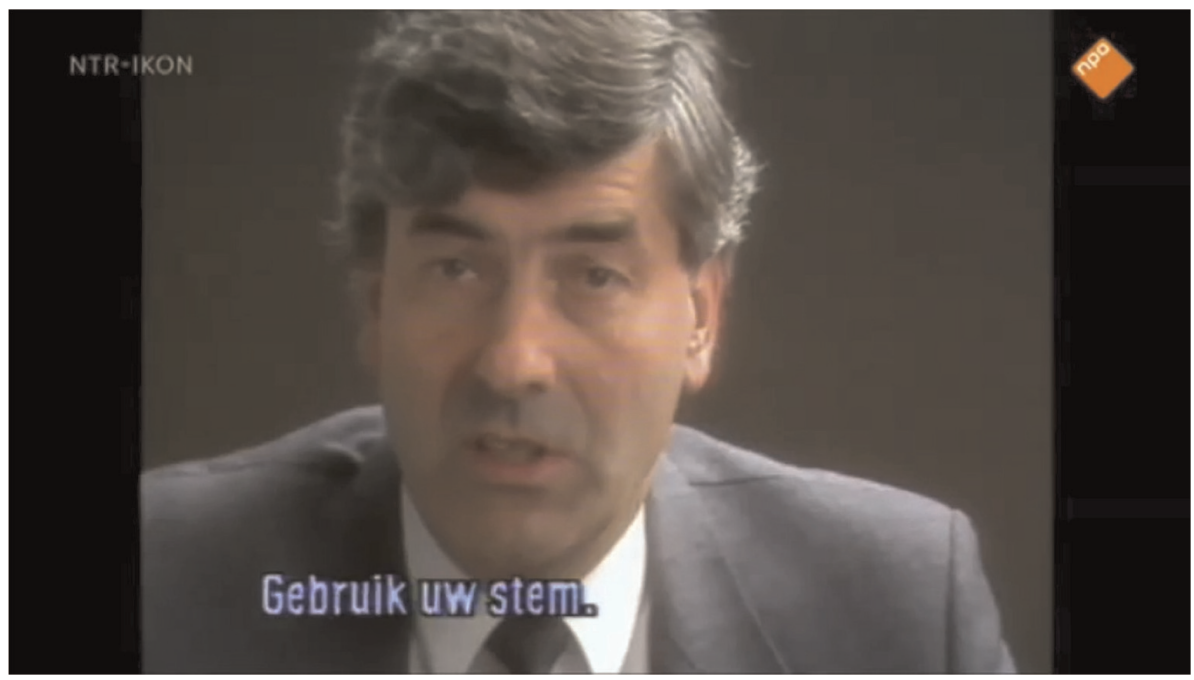

Figure 2. Still from the above described scene in Land of Promise's Episode 2, 'Conflict'

demonstrations in various European cities (26:35-36:36). The familiar footage of banlieus, riots, satellite dishes, migrant youth loitering on the streets, and statements by (populist) politicians does not really add to a better understanding of European immigration history. The cumulative structure of this sequence homogenizes the meaning of this footage and the various images of riots become equivalent and interchangeable. In sequences like this, European immigration history is visualized as a spectacle of conflicts and outbursts of violence.

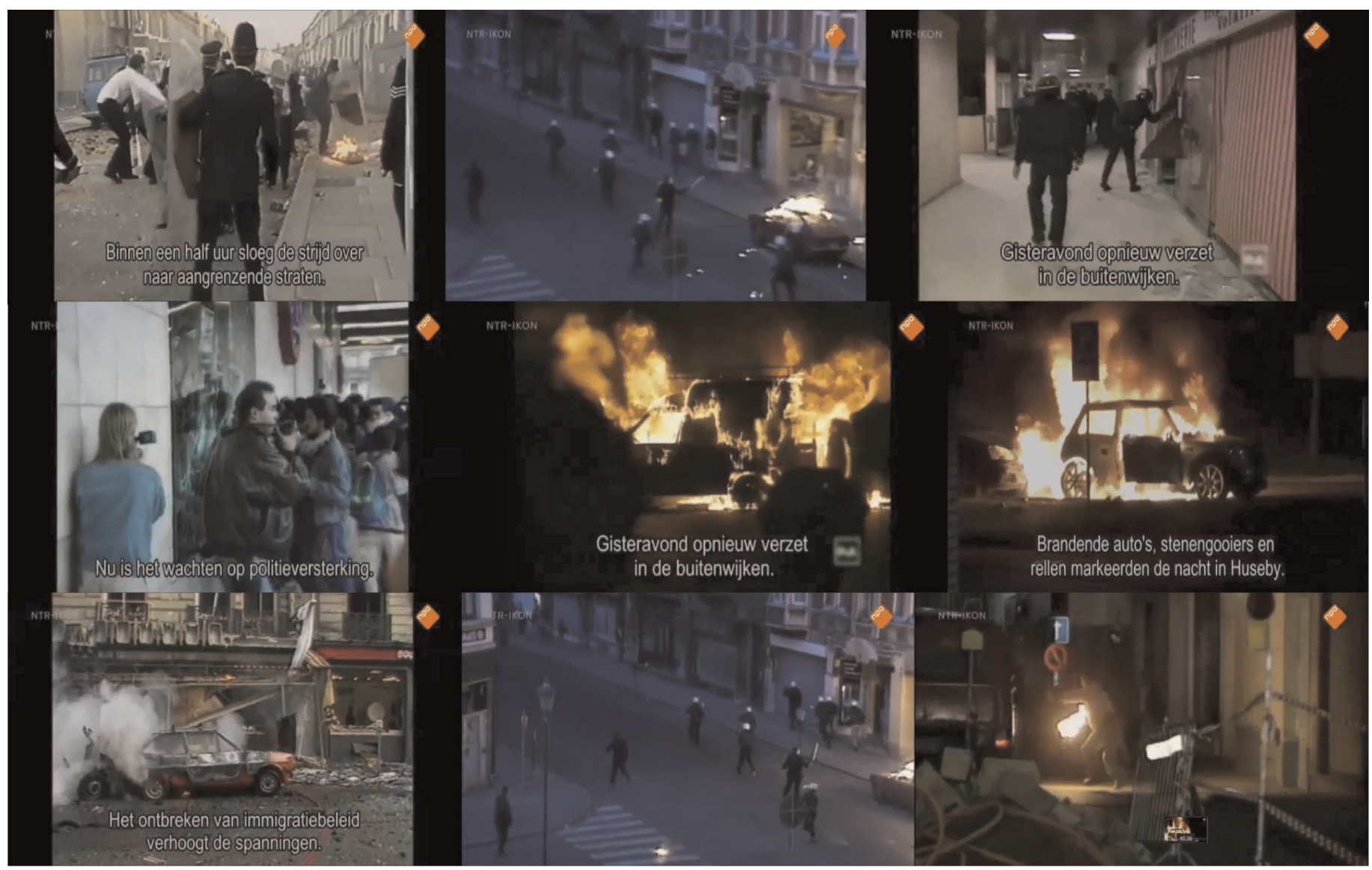

Figure 3. A selection of stills from the above described sequence in Land of Promise's Episode 2, 'Conflict' 
Likewise, the first sequence of Episode 3 (00:00 - 19:25)—which must represent the struggle over the settlement of Islam and show how from "conflict" society enters into "acceptance"-displays not only all the familiar generic (and rather cliché) footage of women with headscarves, domes of mosques, and parades of Muslims, but also all the iconic footage of terrorist attacks, the Rushdie affair, the Danish Cartoon crisis, and the murder of van Gogh. So here the series resorts to footage that is obviously very evocative but has so often been used and repeated by (Dutch) television to visualize the perils of Islam during the last decade and is heavily burdened with connotations of Islamic rage and intolerance. ${ }^{23}$ In this sequence, the very citation of these different historical events - the Rushdie affair, the Cartoon Crisis, the murder of van Gogh-seems to already entail an interpretation. Again, the verbal commentary and the editing generalize the meaning of the various events cited as alike in terms of their underlying causes, anchor a single primary meaning and minimize opportunities for alternative interpretations. In this manner- I would argue — the series contributes to the further development of a television environment in which images lose their historical specificity and become emblematic and in which the visual repertoire of Islam is dominated by a limited amount of compulsively repeated déjà-vu images.

\section{Land of Promise's Selectivity}

Obviously, the makers of Land of Promise have strategically selected archival material that has the capacity to support their preconceived narrative about European immigration history. Necessarily, for every archival image that they have selected, they have excluded alternatives. Like most conventional archive-reliant television programs, Land of Promise's didactic tonality and its seamless interlinking of archival footage conceals this underlying selectivity and invites the viewer to understand the archival images and the imposed narrative as a factual account of history. I want to conclude with a reflection on the selection that the filmmakers have made from the vast amount of Dutch (digitized) archival footage on the topic of immigration that is available in the Institute of Sound and Vision, the Dutch national audio-visual archive. Unfortunately, I have to limit myself to the Dutch case, since I am not familiar with the collections of the other European archives that the filmmakers have used.

Since Land of Promise's account of the initial years of immigration in the first episode revolves around the theme of "avoidance," only footage that fits this theme has been selected. Yet a vast amount of the footage on the initial years of immigration that is available in the archive of Sound and Vision revolves around different forms of contact between Dutch citizens and guest workers during those years. ${ }^{24}$ There is a great deal of footage available that revolves around Dutch who volunteered to teach guest workers the Dutch language, invited them into their homes, helped them with legal problems and their political, social and religious emancipation, and helped to improve their general situation. Thus, footage that depicts the opposite of "avoidance" and that tells an alternative story about the early years of immigration history has been excluded.

The same mechanism is at work in the second and third episode. The series has mobilized all sorts of footage that could illustrate conflicts and polemics over Islam and the settlement of Muslims. This is only a very limited selection of the enormous amount of footage of Muslims that is available. There is a large amount of footage from the sixties and seventies that shows Dutch citizens and Islamic immigrants celebrating Islamic festivals together, such as the Festival of Sacrifice and the Festival of Fast-breaking. ${ }^{25}$ Likewise, there is a lot of footage from the eighties and nineties that show an unproblematic relationship between Dutchmen and Muslims. ${ }^{26}$ In my opinion, by including only material that fits a preconceived narrative that seems for an important part been driven by recent anxieties and obsessions concerning migration and Islam, Land of Promise has missed the opportunity to tell an alternative, new and unfamiliar story about the history of immigration and Muslim presence in Europe. 


\section{Conclusion}

It is likely that, in the near future, the increased amount of available digitized European broadcast material will further intensify television's reliance on its own archive. The ambitious project of Land of Promise demonstrates that the efforts made by European broadcast archives to facilitate the reuse of their holdings open up new possibilities for transnational televisual historiography. While the archival aspirations of Land of Promise are very promising for the new directions that televisual historiography could take, this analysis has shown that archival abundance does not necessarily result in innovative forms of storytelling. In the case of Land of Promise, the selection of the footage and the historicist appropriation strategy are to a large extent the result of the series' aim to convey a preconceived narrative. Besides, its conventional direct-address commentary seems to be prompted by public television's mandate to inform. Hopefully, future television makers will find ways to engage with the available amount of archival material in a more innovative and critical manner. Especially when it comes to contested and delicate issues such as immigration and Islam, in my opinion it could be very rewarding to abandon the conventional use of archival footage and develop new forms of archival compilation and storytelling that are self-reflexive and critical, activate the polemic potential of the material, interrupt television's parading of déjà-vu images, and reflect on the nature of archival footage as media representation.

\section{Biography}

Andrea Meuzelaar is a lecturer at the Department Media and Culture Studies at Utrecht University. She received her MA in Film and Television Studies at the University of Amsterdam. Between 2003 and 2014 she taught at the department of Media and Culture at the University of Amsterdam. In October 2014 she received her PhD from the Amsterdam School of Cultural Analysis. Her PhD research, entitled Seeing through the Archival Prism. A History of the Representation of Muslims on Dutch Television, explores the history of Dutch television coverage of Muslims in the Netherlands, from the arrival of the first Islamic guest workers in the sixties until the recent era of the 2000's, in which Islam became a very contested and salient issue. 